\title{
Synthesis and Characterization of Water Soluble Rosin-Polyethylene Glycol 1500 Derivative
}

\author{
P. Kanlaya, W. Sumrit, and P. Amorn
}

\begin{abstract}
This research aims to synthesize and characterize of rosin-polyethylene glycol derivatives from natural rosin and polyethylene glycol 1500 (PEG1500). In this research, reaction conditions for the synthesis of rosin-PEG derivatives such as catalyst type, catalyst concentration, reaction temperature and etc. were optimized. Chemical and physical properties of water soluble rosin (WSR) were characterized using FT-IR, ${ }^{13} \mathrm{C}$-NMR, DSC, and GPC. It was found that water soluble rosin-PEG derivatives were successful synthesized from natural china rosin and PEG using 2\% $\mathrm{ZnO}$ as catalyst, 2:1 molar ratio of rosin: PEG at $250{ }^{\circ} \mathrm{C}$ for 9 hours. The obtained rosin-PEG1500 derivative were completely soluble in water and rosin-PEG1500 derivative showed melting point at $40.6^{\circ} \mathrm{C}$.
\end{abstract}

Index Terms-Water soluble rosin, polyethylene glycol $\mathbf{1 5 0 0 ,}$ esterification, zinc oxide.

\section{INTRODUCTION}

The development of a sustainable material is one of the most pressing issues for future generations. Energy production and plastic manufacturing produced from fossil fuel has finite availability. Within the next century, it will be nearly depleted. The environmental concerns, along with depleting oil reserves, have led to an increased interest in the development of green material derived from renewable natural resources [1].

One of most interested renewable material is rosin. Rosin or colophony is a renewable, abundant, natural material derived from pin tree and wildly used in the paper, coating, printing ink, polymer, food industries as well as a precursor for flux in soldering [2]. The major compositions of rosin include resin acids represented acids or dimmers or as anhydrides by general formula $\mathrm{C}_{20} \mathrm{H}_{30} \mathrm{O}_{2}$ that are present as free. They are monocarboxylic acids of alkylated hydrophenanthrene; abietic acid constitutes the principal resin acid. [3], [4]. It is soluble in alcohol, ether, benzene and chloroform but insoluble in water Polyethylene glycol (PEG) or poly (ethylene oxide) is petroleum base polymer represent water-soluble mono hydroxy alcohols. These are water-soluble polymers used as base in ointments and suppositories, as plasticizer in film coating, as auxiliary emulsifiers [4], as flux vehicle in WSFs for electronic

Manuscript received July 17, 2015; revised October 15, 2015. This work was supported in part by Mr. Varut Thavivaradilok, the Managing Director of ULTRACORE CO., LTD.

P. Kanlaya is with the Program in Petrochemistry, Faculty of Science, Chulalongkorn University, Bangkok, Thailand (e-mail: Kanlaya.P@Student .chula.ac.th).

W. Sumrit and P. Amorn are with the Department of Chemistry, Faculty of Science, Chulalongkorn University, Bangkok, Thailand (e-mail: sumrit.w@chula.ac.th, amorn.p @chula.ac.th). industrial [5], [6], etc. In the previous study, modification of rosin also improves its safety and stability. The two reactive sites of resin acids - carboxyl group and conjugated double bond - were utilized to synthesize the present ester-adduct derivatives via esterification reaction. Nande et al. (2006, 2007, 2008), Morkhade et al. (2008) synthesized rosin ester derivatives by reacting rosin with PEG, maleic anhydride (MA). Zinc dust was used as a catalyst. The derivatives soluble in organic solvents. Aqueous solubility was $\mathrm{pH}$ dependent and investigated as drug delivery material. Rosin poly (oxyethylene) ester 4,5-dihydroimidazole maleate adduct (RIMA-PEG) was synthesized as corrosion inhibitor for carbon steel [8].

Therefore the purpose of this research was to synthesize and study properties of rosin-polyethylene glycol derivatives from natural rosin and polyethylene glycol (PEG). Catalyst types, catalyst concentrations, reaction temperatures, reaction times, catalyst ratio, PEG type were studied and investigated.

\section{EXPERIMENTAL DETAILS}

\section{A. Material}

Rosin (WW grade) was purchased from Petch Thai Chemical Co, Ltd. and imported from China. PEG 1500, zinc dust, zinc oxide and tin chloride anhydrous were purchased from Merck Co., Ltd.. All the other chemicals were used synthesis grade and were used as received.

\section{B. Study on Optimized Conditions for Synthesis Reaction of Rosin Ester Derivatives}

China rosin (WW grade) was placed in a boiling flask 100 $\mathrm{ml}$. and heated at $100-150{ }^{\circ} \mathrm{C}$ on a heating mantle with stirrer. PEG1500 was mixed with rosin solution using magnetic bar inside set at $750 \mathrm{rpm}$. The temperature of the mixture was studied at $100-250{ }^{\circ} \mathrm{C}$ until the completion of reaction. In this research, zinc dust, zinc oxide and tin chloride were selected and varying concentration of catalyst was study at 0.5-3.0\%. The reaction completion was measured acid number by KEM Automatic Potentiometric Titrator (AT-510) with 0.1 molar of $\mathrm{KOH}$ and use this value for conversion calculation. The molten of the water soluble rosin was poured on aluminum foil cup, allowed to solidify and used as sample for testing.

\section{Characterization of Rosin Ester Derivatives}

Melting point of derivatives was determined by NETZSCH DSC240F1 Phoenix 240-12-0322-L. FT-IR spectroscopy (Perkin Elmer, Spectrum One) was used to determine the functional group of the water soluble rosin. ${ }^{13} \mathrm{C} \mathrm{NMR}$ spectroscopy (Bruker Avance III HD $500 \mathrm{MHz}$ spectrometer) 
was used to confirm ester bonding of rosin derivatives. Molecular weights and polydispersity were measured using gel permeation chromatography with a differential refractometer (model RI-10A; Shimadzu). XRF spectroscopy was used to confirm the present of $\mathrm{Zn}$ in the synthesized product.

\section{RESULTS AND DISCUSSIONS}

\section{A. Optimized Conditions for Synthesis Reaction of the Esterification Reaction}

The target of this reaction was the carboxylic group of rosin reacted with hydroxyl group of PEG to form rosin-PEG derivatives and water via esterification reaction. The sequence of reaction taking abietic as model component is given in Fig. 1. This reaction is reversible reaction that leads to formation of variety products. Products with high ester yield can be obtained either by using catalysts or by use of one of reactant (rosin, PEG) in large excess or by removal of water by increase temperature. Therefore, in this research was to study the effect of catalyst type, catalyst concentration, rosin concentration, reaction temperatures and reaction time on rectification reaction. Reaction conversion was determined by acid value of reactor.

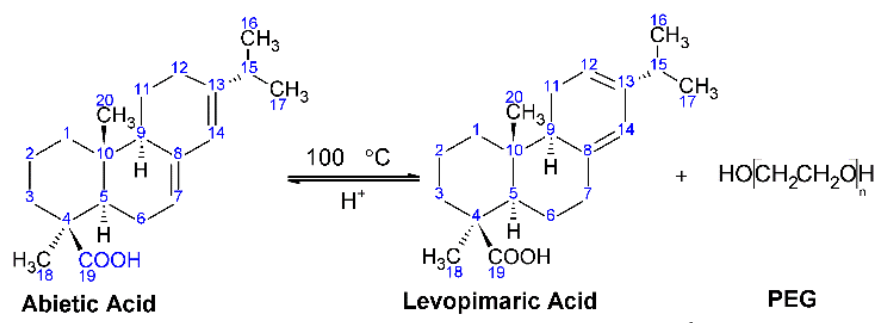

Abietic Acid

Levopimaric Acid

PEG

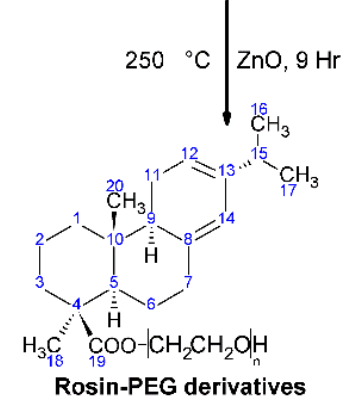

Fig. 1. Reaction scheme of water soluble rosin synthesis.

\section{B. Study of Influence of Catalyst Type on the Esterification Reaction}

In this research $\mathrm{Zn}$-dust, $\mathrm{ZnO}$ and $\mathrm{Tin}$ chloride were selected as catalyst study for esterification reaction of rosin and PEG. Fig. 2 shows conversion percentile of reaction used $\mathrm{Zn}$-dust, $\mathrm{ZnO}$ and Tin chloride. Rate of reaction was significantly increased by all catalysts. Zinc oxide showed the most effective catalyst as it resulted in the highest conversion of ester at 5 hours due to lewis acid performance of this catalyst however zinc dust did not, it may suggest that zinc cation is more readily dissolved from oxide surface into the reaction media comparing with metallic $\mathrm{Zn}$ [9]. Even though zinc oxide and tin chloride are lewis acid but zinc oxide showed higher reaction rate than tin chloride due to moisture and temperature stable of zinc oxide and the result showed consistence with previous studied [10], [11]. Therefore zinc oxide was selected for esterification reaction.

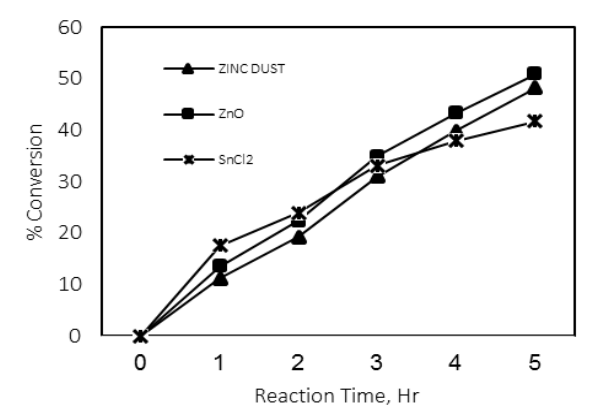

Fig. 2. Conversion (\%) of reaction versus time for the esterification reaction of rosin and PEG1500 using $\mathrm{Zn}$ dust, $\mathrm{SnCl}_{2}$ and $\mathrm{ZnO}$ as catalysts using $0.5 \%$ of catalyst, 1:1 of rosin/PEG @ 2500C for 5 hrs.

\section{Study of Influence of Catalysts Concentration on the Esterification Reaction}

The Fig. 3 shows conversion percentage of reaction and acid value versus catalyst concentration (\%) for the esterification reaction of PEG1500 and $0.5 \%$ zinc oxide at $250{ }^{\circ} \mathrm{C}$ for 5 hours. The data showed that when increased concentration of catalyst from $0.5 \%$ to $2.0 \%$ reaction conversion was increased from $30.2 \%$ to and $69.4 \%$ but decreased to $67.0 \%$ when catalyst concentration was increased up to $3.0 \%$. It can suggest that the increases of the catalyst concentration have a noticeable effect on the conversion rate of the rosin acid into ester derivatives. This fact can be attributed to higher number of molecules of substrate activated by polarization of the carbonyl, in presence of $\mathrm{Zn}^{2+}$ catalyst. Thus, the nucleophilic attack by hydroxyl of PEG becomes more favorable and consequently, an increase on the formation of ester was observed. This result shows consistence with the previous study [12], [13]. Therefore the optimum catalyst concentration was $2 \%$ of rosin content.

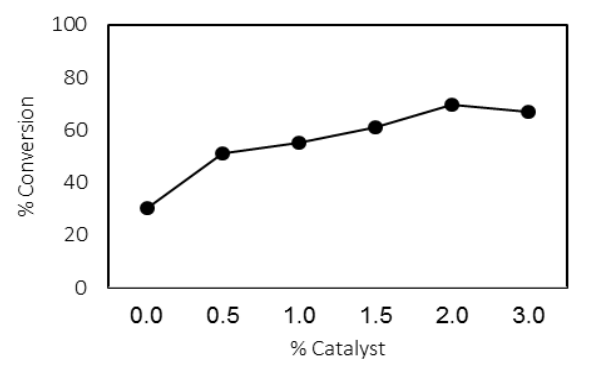

Fig. 3. Conversion (\%) of the esterification reaction between rosin and PEG1500 using catalyst concentration 0\% to $2 \%$ @250OC for $5 \mathrm{hrs}$.

\section{Study of Influence of Temperature on the Esterification Reaction}

In this study, reaction temperature at 100, 150, 200, 225, $250{ }^{\mathrm{O}} \mathrm{C}$ for 5 hours was selected for investigation of reaction temperature effect. Table II shows the summary of test result of rosin derivatives at $100,150,200,225,250{ }^{\circ} \mathrm{C}$ for 5 hours. The results shows that, the acid value of reactants did not change at $100{ }^{\circ} \mathrm{C}$ and dropped when reaction temperature was increased to $150,200,225,250^{\circ} \mathrm{C}$. From data it can conclude that at $100{ }^{\circ} \mathrm{C}$ reaction of rosin and PEG was not occurred and increased when reaction temperature was raise due to water 
molecule was faster removed and materials were converted into esters of rosin. Water solubility of synthesized product was higher at $250{ }^{\circ} \mathrm{C}$. This result shows consistence with the previous study [13]-[15]. Therefore the optimum reaction temperature was $250^{\circ} \mathrm{C}$.

TABLE I: CONVERSION PERCENTAGE, ACID VALUE AND WATER SOLUBILITY OF REACTION AT TEMPERATURE $100,150,200,225,250{ }^{\circ} \mathrm{C}$.

\begin{tabular}{|c|c|c|c|c|}
\hline $\begin{array}{c}\text { Reaction } \\
\text { Temperature, } \\
{ }^{\circ} \mathrm{C} \\
\end{array}$ & $\begin{array}{c}\text { Acid Value } \\
\text { start }\end{array}$ & $\begin{array}{c}\text { Acid Value } \\
5 \text { hr, } \\
\text { (mg. KOH/g) }\end{array}$ & $\begin{array}{c}\% \\
\text { conversion }\end{array}$ & $\begin{array}{c}\begin{array}{c}\text { Water } \\
\text { solubility } \\
\text { g/ml }\end{array} \\
\end{array}$ \\
\hline 100 & 46.5 & 47.6 & 0.0 & 0.35 \\
\hline 150 & 47.02 & 43.9 & 6.5 & 0.24 \\
\hline 200 & 49.0 & 44.92 & 8.2 & 0.00 \\
\hline 225 & 49.56 & 41.3 & 16.7 & 0.01 \\
\hline 250 & 47.4 & 16.4 & 65.5 & 0.96 \\
\hline
\end{tabular}

\section{E. Study of Influence of the Rosin/PEG Ratio on the Esterification Reaction}

The rosin to PEG molar ratio is one of the important parameter that affecting the rosin acid conversion to rosin ester derivatives. The effect of rosin to PEG molar ratio molar ratio on conversion of rosin acid was investigated at fixed temperature at $250{ }^{\circ} \mathrm{C}$ and catalyst concentration at $2 \%$. Fig. 4 represent rate of esterification reaction at the various concentration ratio of rosin: PEG. It was found that the reaction rate of rosin acid to rosin ester derivatives was 15.72 mmol.hr ${ }^{-1}$ at 2:1 molar ratio of rosin to PEG. The optimum molar ratio of rosin to PEG was 2:1.

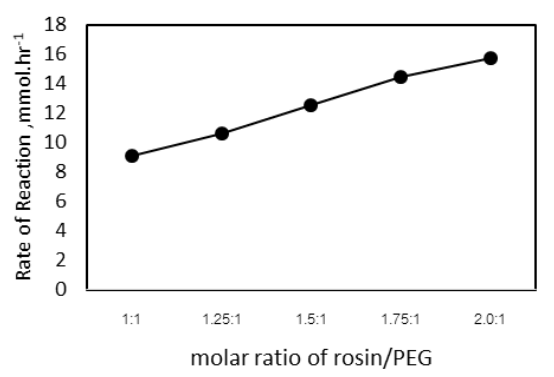

Fig. 4. Rate of reaction of esterification reaction using difference rosin/PEG ratio using $\mathrm{ZnO} 2 \%$ @ $250{ }^{\circ} \mathrm{C}$ for $5 \mathrm{hrs}$.

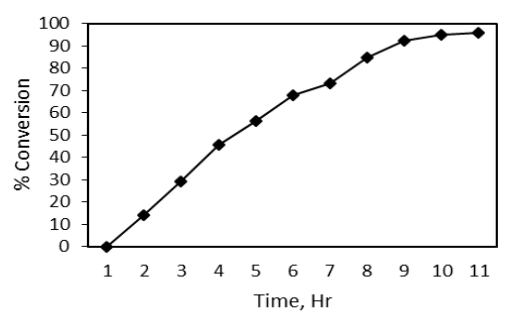

Fig. 5. Conversion (\%)of esterification reaction using $\mathrm{ZnO} 2 \%, 2: 1$ of rosin: PEG1500@ $250{ }^{\circ} \mathrm{C}$ for $10 \mathrm{hrs}$.

\section{F. Study of Influence of the Rosin/PEG Ratio on the Esterification Reaction}

The highest of conversion of rosin and PEG to rosin ester derivative is expectation of this study therefore increasing time was investigated. Effect of reaction time to conversion of esterification reaction is represented in Fig. 5. The result showed that when increased reaction time from one to eight hours reaction conversion was significantly increased and seems constant from nine to ten hours. And reaction time at nine hours was suggested to optimum reaction time with $95 \%$ conversion.

\section{G. Characterizations of Rosin Derivatives}

In this study, FT-IR and ${ }^{13} \mathrm{C}$ NMR spectroscopy were the technique for characterization and confirmation of ester bond formation of rosin ester derivatives. Fig. 6 presents the IR spectra of rosin, PEG, rosin derivative at 0 hour, 5 , hours and 10 hours respectively. The IR spectra of China rosin, $\mathrm{C}=\mathrm{O}$ stretching at $1690 \mathrm{~cm}^{-1}$ and $\mathrm{O}-\mathrm{H}$ stretching at $3568 \mathrm{~cm}^{-1}$ indicated that the presence of carboxylic acid in rosin. The IR spectra of derivatives at 0 hour show $\mathrm{C}=\mathrm{O}$ stretching ratio at $1690 \mathrm{~cm}^{-1}$ higher than $1721 \mathrm{~cm}^{-1}$ and reduced when the reaction time was increased suggested that the conversion of acid to ester was occurred and increased when increasing reaction time. This is consistent with the previous study [14]. These results suggest that ester group presented in all kinds of rosin-PEG derivatives. The ${ }^{13} \mathrm{C}$ NMR spectra of all rosin-PEG derivatives were presented in Fig. 8, the chemical shift around $180 \mathrm{ppm}$ support that the ester bond created in all rosin-PEG derivatives and these findings are consistent with the previous study [16]-[18]. From all results, the sequence of reaction can be proposed as given in Fig. 1.

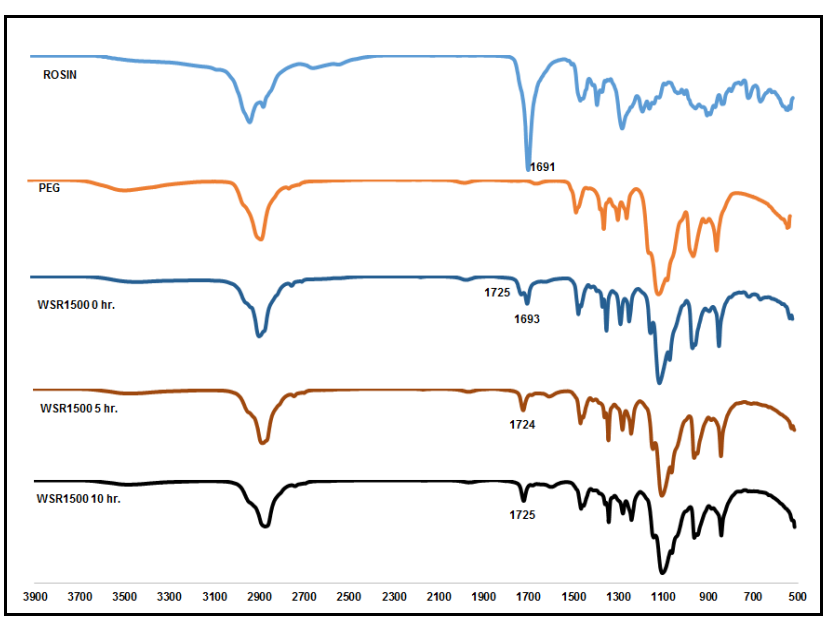

Fig. 6. Infrared spectra of China rosin, PEG and the Rosin-PEG1500 derivative at $0,5,10 \mathrm{hrs}$.

\section{H. Characteristic of Water Soluble Rosin-PEG Derivatives}

Fig. 7 presents the DSC spectra of rosin-PEG derivatives, it appears that the melting point of derivatives was decreased from native rosin and increase when molecular weight of PEG increased. Water solubility of all rosin-PEG derivatives were $100 \%$, it can suggested that the carboxylic group in rosin reacted with hydroxyl group in PEG1500 and yielded ester bond. These effected to increasing water solubility property of native rosin therefore rosin-PEG derivatives were dissolved in water via hydroxyl group in PEG molecule.

Fig. 9 shows XRF spectra of $\mathrm{Zn}$ content in rosin-PEG derivatives. This data indicated that $\mathrm{Zn}$ still remained in the final synthesized product and dissolve in water. The results 
showed that $\% \mathrm{Zn}$ contained in rosin-PEG1500 derivatives was $0.606 \%$. It may assume that $\mathrm{ZnO}$ used as catalyst was changed from $\mathrm{ZnO}$ in to acetate form which dissolve in water.

The physical and chemical properties of rosin, PEG and WSRs are summarized in Table II. From the results shows that all kind of PEGs showed excellent water solubility and melting temperature of WSR 1500 was $40.6^{\circ} \mathrm{C}$ and lower than native rosin and PEG1500. From this result it can suggest than melting point of derivative was affected from rosin content and melting point of PEG. This result shows consistent with previous study [4], [14], [19].

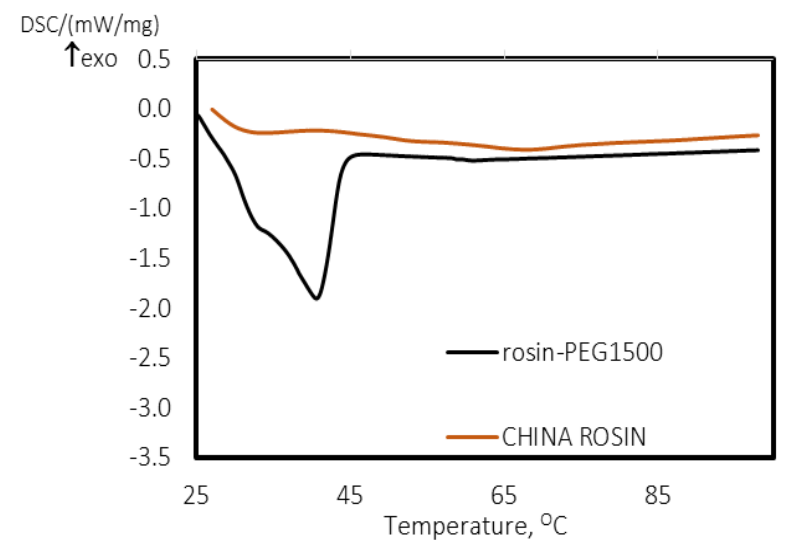

Fig. 7. DSC spectra of China rosin and rosin-PEG 1500 derivatives.

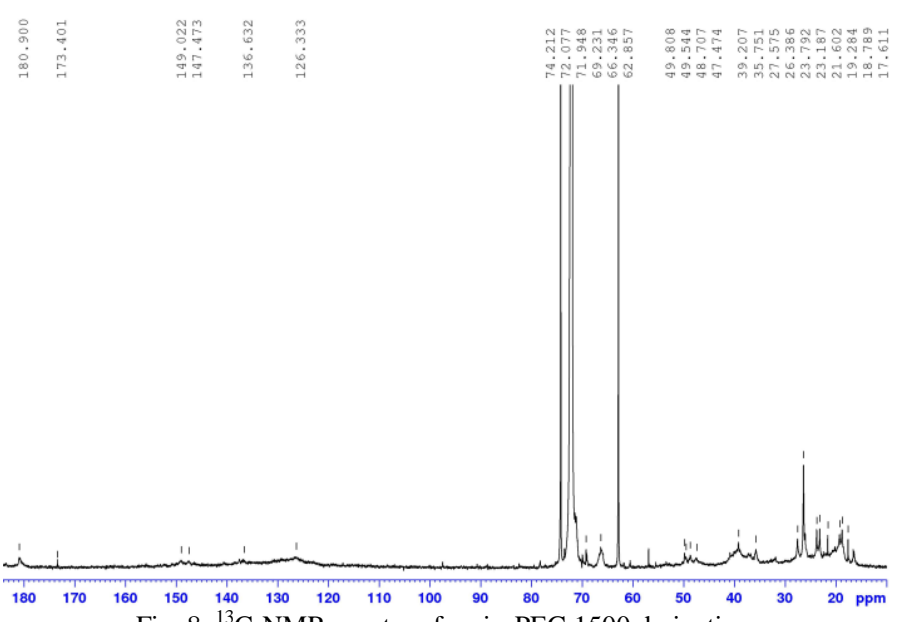

Fig. $8 .{ }^{13} \mathrm{C}-\mathrm{NMR}$ spectra of rosin-PEG 1500 derivatives.

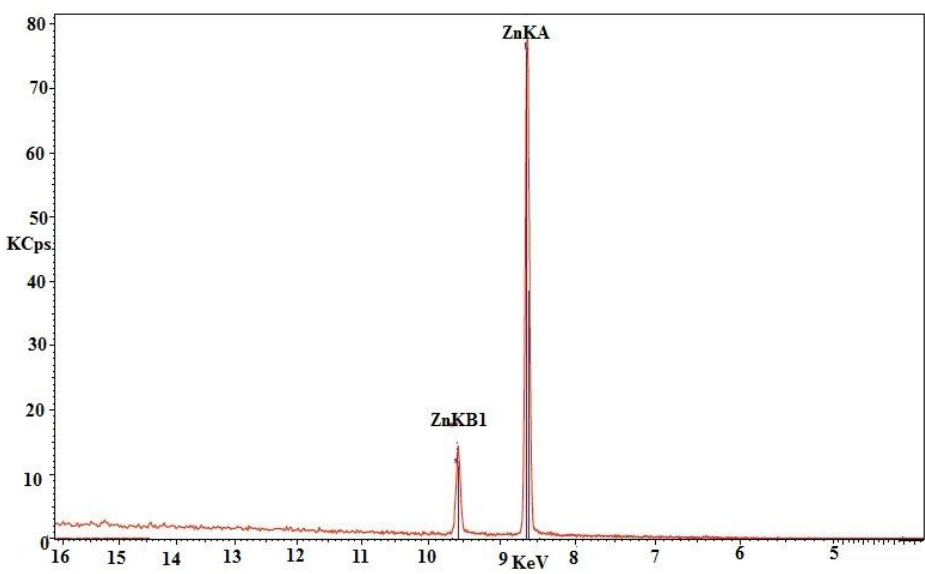

Fig. 9. XRF spectrum of Zn in rosin-PEG 1500 derivatives.
TABLE II: PHYSICAL AND CHEMICAL PROPERTIES OF WSRS

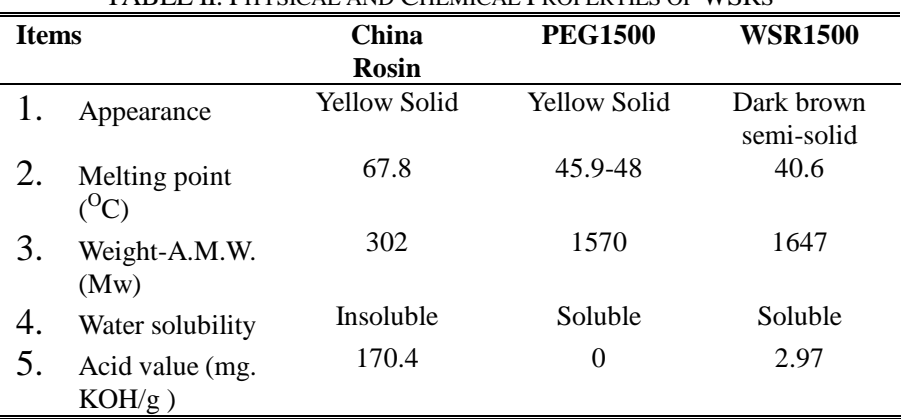

\section{CONCLUSION}

Rosin-PEG 1500 derivatives were successful synthesis from natural rosin and PEG using $\mathrm{ZnO} 2 \%$ as catalyst, 2 molar of rosin at $250{ }^{\circ} \mathrm{C}$ for 9 hours. This derivatives were completely soluble in water then we can call water soluble rosin (WSR). WSR1500 showed melting point at $40.6{ }^{\circ} \mathrm{C}$ but lower than native rosin. Acid value was $2.97 \mathrm{mg}$. $\mathrm{KOH} / \mathrm{g}$ and $95 \%$ conversion at 9 hours. A.M.W. (Mw) of this derivatives were 1647.

\section{REFERENCES}

[1] P. A. Wilbon, F. Chu, and C. Tang, "Progress in renewable polymers from natural terpenes, terpenoids, and rosin," Macromol Rapid Commun, vol. 34, pp. 8-37, January 2013.

[2] M. Ladero, M. de Gracia, J. J. Tamayo, I. L. D. Ahumada, F. Trujillo, and F. Garcia-Ochoa, "Kinetic modelling of the esterification of rosin and glycerol: Application to industrial operation," Chemical Engineering Journal, vol. 169, pp. 319-328, 2011.

[3] V. S. Nande, U. V. Barabde, D. M. Morkhade, S. B. Joshi, and A. T. Patil, "Investigation of PEGylated derivatives of rosin as sustained release film formers," AAPS PharmSciTech, vol. 9, pp. 105-111, 2008.

[4] V. S. Nande, U. V. Barabde, D. M. Morkhade, A. T. Patil, and S. B. Joshi, "Synthesis and characterization of PEGylated derivatives of rosin for sustained drug delivery," Reactive and Functional Polymers, vol. 66, pp. 1373-1383, 2006.

[5] J. S. Hwang, "Alkali metal hydroxide in polyol flux, water soluble synthetic wax," US Patent 4460414, 1984.

[6] W. Jacobs, "Water soluble activator is mixture of alkylamine acid salt, lower alkanol amine, organic acid, (poly)ethylene glycols," US Paten 4872928, 1989.

[7] V. S. Nande, U. U. Barabde, D. M. Morkhade, A. T. Patil, and S. B. Joshi, "Sustained release microspheres of diclofenac sodium using PEGylated rosin derivatives," Drug Dev Ind Pharm, vol. 33, pp. 1090-100, Oct. 2007.

[8] G. El-Mahdy, A. M. Atta, and H. A. Al-Lohedan, "Water soluble Nonionic Rosin Surfactants As Corrosion Inhibitor of carbon steel in 1M HCl," Int. J. Electrochem. Sci, vol. 8, pp. 5052-5066, 2013.

[9] H. Hattori, M. Misono, and Y. Ono, Acid-base Catalysis II: Elsevier, 1994.

[10] F. Tamaddon, M. A. Amrollahi, and L. Sharafat, "A green protocol for chemoselective O-acylation in the presence of zinc oxide as a heterogeneous, reusable and eco-friendly catalyst," Tetrahedron Letters, vol. 46, pp. 7841-7844, 2005.

[11] P. Kulkarni, " $\mathrm{Al}_{2}\left(\mathrm{SO}_{4}\right)_{3}$ is an efficient and mild acid catalyst for the one-pot, four-component synthesis of polyhydroquinoline," Journal of the Chilean Chemical Society, vol. 59, pp. 2319-2321, 2014.

[12] M. R. Uddin, K. Ferdous, M. R. Uddin, M. R. Khan, and M. A. Islam, "Synthesis of biodiesel from waste cooking oil," Chemical Engineering and Science, vol. 1, pp. 22-26, 2013.

[13] A. L. Cardoso, S. C. G. Neves, and M. J. da Silva, "Esterification of oleic acid for biodiesel production catalyzed by $\mathrm{SnCl}_{2}$ : A kinetic investigation," Energies, vol. 1, pp. 79-92, 2008.

[14] D. M. Morkhade, V. S. Nande, U. V. Barabde, M. U. Kamble, A. T. Patil, and S. B. Joshi, "A comparative study of aqueous and organic-based films and coatings of PEGylated rosin derivative," Drug Dev Ind Pharm, vol. 34, pp. 24-32, Jan. 2008. 
[15] Y. Liu, E. Lotero, and J. G. Goodwin, "Effect of water on sulfuric acid catalyzed esterification," Journal of Molecular Catalysis A: Chemical, vol. 245, pp. 132-140, 2006.

[16] M. I. B. Tavares, L. C. Mendes, R. S. Cardoso, N. B. Sanches, and B. S. Chagas, "13C NMR Study PP/ROSIN Blends," International Journal of Polymeric Materials, vol. 46, pp. 793-799, 2000.

[17] S. C. Hess, M. I. S. Farah, S. Y. Eguchib, and P. M. Imamura, "Synthetic studies with Pinus elliottiis rosin derivatives. Oxidation of maleopimaric anhydride methyl ester and trimethyl fumaropimarate," Journal of the Brazilian Chemical Society, vol. 11, pp. 59-63, 2000.

[18] W. B. Smith, "The 13C NMR spectrum of abietic acid and its methyl ester," Organic Magnetic Resonance, vol. 11, pp. 427-428, 1978.

[19] D. Morkhade, V. Nande, U. Barabde, A. Patil, and S. Joshi, "PEGylated rosin derivatives: Novel microencapsulating materials for sustained drug delivery," AAPS PharmSciTech, vol. 8, 2006.

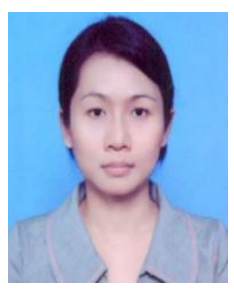

Kanlaya Phaphon was born on September 1, 1977. She received her bachelor's degree of science in chemistry from Faculty of Science, Chulalongkorn University in 1999. She began her master study in Program of the Petrochemistry and Polymer Science, the Faculty of Science, Chulalongkorn University in 2002 , and completed the program in 2004. She began her Ph.D degree in Program of Petrochemistry, Faculty of Science in 2011.

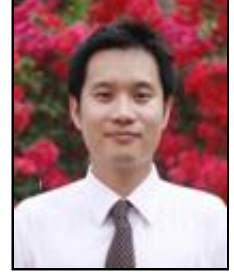

Sumrit Wacharasindhu received his bachelor's degree in chemistry from Chulalongkorn University, Bangkok, Thailand, and his Ph.D. in organic chemistry from the University of Missouri, Columbia in the United States. He is Lecturer and Assistant Professor at Chulalongkorn University. His current research goal is to create methods to prepare organic compounds in robust, convenient, and generation of hazardous waste. environmentally friendly ways with reduced

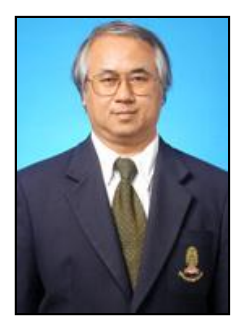

Amorn Petsom received his bachelor's degree in chemistry from Chulalongkorn University, Bangkok, Thailand, and his Ph.D. in organic chemistry from the University of Arizona (Tucson) in the United States. He became a lecturer at Chulalongkorn University in 1976 and an associate professor there in 1998. His research focuses include natural products, biotechnology, and petrochemistry. Currently, he serves as the director of the Scientific Chulalongkorn University. and Technological Research Equipment Center of 
